\title{
A Sociedade Brasileira de Educação Matemática e as Políticas Educacionais
}

\section{La Sociedad Brasileña de Educación Matemática y las Políticas Educativas}

\author{
Elisabete Zardo Búrigo*
}

ORCID iD 0000-0003-1532-7586

Nos debates sobre a trajetória de 30 anos da nossa Sociedade Brasileira de Educação Brasileira $(\mathrm{SBEM})^{1}$, recebi a incumbência de propor uma reflexão sobre a Sociedade e as políticas educacionais.

Falar de políticas educacionais no Brasil pressupõe buscar, dentre a vasta produção sobre o tema, algumas referências que serão explicitadas ao longo do texto. No que diz respeito à SBEM, as provocações que apresento tomam como base as produções e materiais coletados por Pereira (2005) e Muniz (2013) e documentos disponíveis na página da entidade: estatuto, atas de reuniões e Assembleias Gerais, boletins, cartas, moções, sumários dos anais de eventos e textos identificados como pertinentes para esta discussão, a partir do exame desses sumários.

Segundo nosso estatuto, é uma finalidade da SBEM "Atuar, [...] junto aos órgãos governamentais na formulação, implementação e avaliação de políticas nacionais de educação e, em especial, as relacionadas à Educação Matemática" (SBEM, 2013, p. 2$)^{2}$.

Mas, quais foram as políticas consideradas merecedoras de debate ou de manifestação por parte da Sociedade e como se deram esses debates? Como se modificaram, ao longo desses trinta anos, os modos de pensar, de incidir ou de se posicionar frente às políticas

\footnotetext{
* Doutora em Educação pela Universidade de São Paulo (USP). Professora Associada da Universidade Federal do Rio Grande do Sul, Porto Alegre, Rio Grande do Sul, Brasil. Endereço para correspondência: Av. Bento Gonçalves, 9500, Prédio 43111, Caixa Postal 15080, Bairro Agronomia, Porto Alegre, Rio Grande do Sul, Brasil. CEP: 91509-900. E-mail: elisabete.burigo@ufrgs.br.

${ }^{1}$ Texto apresentado à Mesa-Redonda "A Pesquisa em Educação Matemática nos 30 anos de SBEM", no VII Seminário Internacional de Pesquisa em Educação Matemática, Foz do Iguaçu, em 7 de novembro de 2018. A leitura comentada do texto foi precedida por discussão apresentada pelo coordenador da mesa, Wagner Rodrigues Valente, e pela exposição de Filipe Santos Fernandes. Um texto construído a partir das duas falas foi apresentada como editorial do número anterior do Bolema.

${ }^{2} \mathrm{O}$ estatuto atual foi aprovado em Assembleia Geral Ordinária realizada em 21 de julho de 2013. A redação do inciso é quase idêntica à do Estatuto original, aprovado em 27 de janeiro de 1988: "Atuar junto aos órgãos governamentais na formulação, execução e avaliação da Política Nacional de Educação e, em especial, da EM" (SBEM apud PEREIRA, 2005, p. 217).
} 
educacionais? Quais valores ou princípios motivaram o engajamento da SBEM na discussão e implementação das políticas?

No primeiro projeto de estatuto da Sociedade, aprovado ao final do I Encontro Nacional de Educação Matemática (ENEM), em fevereiro de 1987, constava o princípio orientador de "promover e defender o direito de todos a uma Educação Matemática libertadora e democrática, acessível a todos" (PEREIRA, 2005, p. 156). No último dia 18 de outubro, entre o primeiro e o segundo turno das últimas eleições presidenciais, a diretoria da SBEM publicou uma nota em que declara o alinhamento da nossa Sociedade "com a opção pela Escola para a reflexão, criatividade, produção de saberes, autonomia e liberdade" (SBEM, 2018). Podemos pensar nesse texto recente como uma atualização daquele, produzido em 1987 ?

\section{Avanços, impasses e tensões na vigência da Constituição Cidadã}

O aniversário da Sociedade corresponde aos trinta anos de vigência da Constituição de 1988, que tem sido denominada "Constituição Cidadã". Uma Constituição que nunca foi implementada e respeitada na sua plenitude, mas que instituiu avanços hoje ameaçados; dentre eles, o da liberdade de ensinar e aprender e os percentuais mínimos de gastos das receitas de impostos com a educação, por parte da União, dos Estados e municípios ${ }^{3}$ (BRASIL, 1988).

O cenário em que nos movemos ao longo desses trinta anos, é, portanto, o da configuração e instalação de uma nova institucionalidade. Após a promulgação da Constituição, tivemos oito anos de debate até a aprovação da Lei de Diretrizes e Bases da Educação Nacional (LDBEN), em 1996, que institui, dentre outras novidades, a figura da Educação Básica, abarcando a Educação Infantil e a progressiva universalização do Ensino Médio gratuito; e o requisito da licenciatura plena como formação mínima para atuação de professores nos anos finais do Ensino Fundamental e no Ensino Médio (BRASIL, 1996).

Por sua vez, o primeiro Plano Nacional de Educação (PNE), aprovado em 2001, foi, na prática, substituído em 2007 pelo Plano de Desenvolvimento de Educação (PDE) (SAVIANI, 2008); e, em 2014, tivemos a aprovação do segundo PNE, que estabelece vinte metas para o decênio (BRASIL, 2014a). Já numa onda regressiva temos, em 2016, a aprovação da Emenda Constitucional $n^{\circ} 95$, que suspende a garantia dos percentuais mínimos constitucionais de

\footnotetext{
${ }^{3}$ Inscritos, respectivamente, em seus artigos 206 e 212.
} 
gastos com o ensino ${ }^{4}$, e em 2017 uma ampla revisão da LDB a partir da Lei $n^{0} 13.415$, que institui a chamada reforma do Ensino Médio, e a recente homologação da Base Nacional Curricular Comum (BNCC) para o Ensino Fundamental ${ }^{5}$.

A ampliação do acesso à Educação Básica é, em boa medida, decorrente das mudanças no plano da legislação e do financiamento. Em 1985, a escolaridade média dos brasileiros era de aproximadamente quatro anos; $82 \%$ das crianças de 7 a 14 anos frequentavam a escola, mas apenas 59\% dos jovens de 15 a 17 anos estudavam (INEP, 1996). Já em 2002, o Ensino Fundamental abrangia 97\% da faixa etária (OLIVEIRA, 2007) e, no ano de 2016, 87\% dos jovens de 15 a 17 anos estudavam ${ }^{6}$. Em um contexto de ampliação do financiamento e de uma institucionalidade democrática, também se produziram avanços, como a instituição do Piso Salarial Nacional para Profissionais do Magistério Público da Educação Básica, a multiplicação de programas de formação continuada e a expansão da pós-graduação.

Como um componente importante dessa expansão, temos a constituição de uma importante rede de programas de pós-graduação em Educação Matemática e/ou de linhas de pesquisa em Educação Matemática no interior dos programas em Educação.

Ao tempo da fundação da SBEM, havia apenas o programa da Universidade Estadual Paulista (Unesp), em Rio Claro. No início dos anos 1990, foram constituídos os programas da Universidade de Santa Úrsula e da Pontifícia Universidade Católica (PUC) de São Paulo (FIORENTINI, 1994). Já em 2017, apenas na área Ensino da Capes, havia 54 programas intitulados como Educação Matemática, Ensino de Matemática ou Ensino de Ciências e Matemática, além das linhas de pesquisa abrigadas em programas de Educação ou em programas de Ensino mais abrangentes e da Rede Amazônica de Ensino de Ciências e Matemática (REAMEC) ${ }^{7}$.

Todas essas mudanças compõem o cenário de movimentações da SBEM. Entretanto, seria bastante simplista e, na minha opinião, equivocado, pensar nesse período como um

\footnotetext{
${ }^{4}$ Conforme Artigo 110 do Ato das Disposições Constitucionais Transitórias (BRASIL, 2016).

5 A Resolução n ${ }^{\circ}$ 2/2017 do Conselho Pleno do Conselho Nacional de Educação, que institui e orienta a implantação da Base Nacional Comum Curricular na Educação Infantil e no Ensino Fundamental, é complementada por documento técnico do Ministério da Educação também publicado em dezembro de 2017. A Resolução no 4/2018 do Conselho Pleno do Conselho Nacional de Educação, que institui a Base Nacional Comum Curricular na Etapa do Ensino Médio, é posterior à Mesa-Redonda em que o texto foi apresentado.

${ }^{6}$ Segundo dados da Pesquisa Nacional por Amostra de Domicílios Contínua (PNAD Contínua), realizada pelo Instituto Brasileiro de Geografia e Estatística (IBGE), disponíveis em: <https://agenciadenoticias.ibge.gov.br/ agencia-sala-de-imprensa/2013-agencia-de-noticias/releases/18992-pnad-continua-2016-51-da-populacao-com25-anos-ou-mais-do-brasil-possuiam-apenas-o-ensino-fundamental-completo>. Acesso em: 5 nov. 2018.

${ }^{7}$ Dados extraídos do Relatório de Avaliação da Área Ensino da CAPES, disponível em: <http://www.capes.gov .br/images/stories/download/avaliacao/relatorios-finais-quadrienal-2017/20122017-ENSINO-quadrienal.pdf >. Acesso em: 5 dez. 2018.
} 
encadeamento de avanços e conquistas, que teriam sido interrompidos nos últimos dois anos.

De um lado, porque o problema do financiamento nunca foi equacionado (SAVIANI, 2008; FRIGOTTO, 2011; BRASIL, 2015a; CAMPANHA NACIONAL PELO DIREITO À EDUCAÇÃO, 2018). As políticas de valorização dos profissionais da Educação foram solapadas pela precarização das contratações e condições de trabalho nas redes estaduais. Políticas de otimização de recursos vêm justificando, inclusive, o fechamento de escolas, contrariando a lógica da educação escolar construída segundo as demandas das comunidades.

De outro lado, ao mesmo tempo em que a educação pública se expande, sofre diversas pressões para se adequar aos interesses do empresariado. Parte dessas pressões chega pelas avaliações em larga escala - Programa Internacional de Avaliação de Estudantes (PISA), Sistema de Avaliação da Educação Básica (SAEB), Exame Nacional do Ensino Médio (ENEM) e Provão, depois convertido em Exame Nacional de Desempenho dos Estudantes (ENADE). Todas essas avaliações instituem as ideias de que: a educação escolar tem como finalidade central a constituição de competências, e a matemática ganha um lugar de destaque segundo essa perspectiva; a qualidade do ensino pode ser medida pelo desempenho de estudantes em provas; é possível comparar a qualidade do ensino de redes e instituições por meio de índices (FRIGOTTO, 2011; CABRITO, 2009).

Em 2007, sob a pressão do empresariado articulado em torno da campanha Todos pela Educação, é instituído o Índice de Desenvolvimento da Educação Básica (IDEB), que passa a ser o grande mecanismo regulador de políticas em vários níveis e, inclusive, da ação docente nas salas de aula (SAVIANI, 2008). A partir de 2013, com a constituição do Movimento pela Base Nacional Comum, assistimos a uma nova investida do setor empresarial, agora buscando incidir diretamente nos currículos escolares, ressignificando a noção de "direitos de aprendizagem" como "objetivos de aprendizagem", acenando para a padronização de materiais didáticos e de formação de professores, sempre sob os signos da escolarização eficaz e da constituição de sujeitos competentes (MACEDO, 2014).

As pressões para a padronização do ensino, por outro lado, não têm origem apenas no campo empresarial. De fato, a tensão entre os princípios da igualdade e da diversidade está presente no debate educacional desde os anos 1980. A diversidade é contemplada no Artigo 15 da LDBEN, que prevê progressivos graus de autonomia pedagógica e administrativa para as escolas; é reivindicada pelos movimentos sociais e reconhecida em vários documentos normativos, como as Diretrizes da Educação de Jovens e Adultos ou para as Escolas do 
$\mathrm{Campo}^{8}$. O preceito da igualdade está presente nas reivindicações de acesso à escola, "para todos", e no debate mais recente sobre as expectativas e os "direitos de aprendizagem" (BRASIL, 2014b). Entretanto, percebe-se um deslocamento progressivo da ideia, presente na LDBEN, do direito à igualdade nas condições de oferta do ensino, aí incluídos os patamares de formação e de remuneração dos professores, na direção da igualdade imposta pela via da uniformização dos currículos, em vários níveis e modalidades. Na formação de professores que ensinam matemática, assistimos à expansão das licenciaturas via educação a distância, e à instituição do Mestrado Profissional em Rede, proposto pela Sociedade Brasileira de Matemática (SBM), baseado na padronização de aulas, leituras e da avaliação (SBM, 2018; SBEM, 2010b). E, finalmente, a BNCC se instala como um grande instrumento de padronização da Educação Básica, articulado ao IDEB e aos sistemas de avaliação.

Quanto aos recursos públicos, é importante considerar que sua ampliação abre novos campos de intervenção para os educadores matemáticos, na esfera da formação continuada de professores, da produção de livros e materiais didáticos, mas também mobiliza outros atores. A SBM é um deles e intervém nesse processo com suas próprias concepções sobre o ensino de matemática e a formação de professores, em termos e em condições diferentes daquelas que caracterizavam o contexto da época da fundação da SBEM (SBEM, 2003b; 2010b).

A produção e implementação das políticas educacionais é marcada, então, pela disputa dos recursos públicos, pelas tensões entre interesses públicos e privados, pelas tensões entre a valorização da diversidade e as pressões na direção da padronização da educação escolar.

\section{A SBEM face às políticas educacionais}

Retomando as questões iniciais: quais foram as políticas consideradas merecedoras de debate ou de manifestação por parte da Sociedade e como se deram esses debates? Como se modificaram, ao longo desses trinta anos, os modos de pensar, de incidir ou de se posicionar frente às políticas educacionais?

Sabemos que governos e legisladores não são os únicos atores a propor e implementar ações que produzem efeitos na esfera educacional. Tentando delimitar o âmbito da discussão, entretanto, proponho enfocar aquelas políticas de âmbito nacional e que se originam de iniciativa governamental ou legislativa, ou contam com chancela de alguma dessas instâncias

\footnotetext{
${ }^{8}$ Respectivamente, Resolução no 1/2000 e Resolução nº 1/2002 da Câmara de Educação Básica do Conselho Nacional de Educação.
} 
e são implementadas com o uso de recursos públicos. Também proponho não considerar, nesta discussão, as participações de membros da SBEM na implementação de políticas, resultantes de convites ou escolhas individuais, mas tomar como objeto de reflexão os debates que visam produzir algum tipo de posicionamento por parte da Sociedade.

Para organizar minhas provocações, trago três exemplos de temas que, na minha avaliação, mereceram muito pouco, algum ou muito debate por parte da SBEM.

Inicio mencionando um exemplo de política cuja implementação contou com a participação de educadores matemáticos, membros da SBEM, mas foi pouco debatida nos fóruns da Sociedade: as avaliações em larga escala.

Uma carta do então Presidente da SBEM, Cristiano Muniz, ao Ministro Fernando Haddad, em 2010, menciona que

\begin{abstract}
A SBEM tem pautado sua história pela forte participação de seus educadores matemáticos na concepção, desenvolvimento e implantação de importantes políticas públicas na área educacional, tais como SAEB, PROVA BRASIL, ENEM, ENADE, ENCEJA, PNLD, GESTAR, Pró-Formação e, mais recentemente, Pró-Letramento (SBEM, 2010a, p. 1).
\end{abstract}

Sem que sejam mencionados nomes ou processos de indicação, encontramos aqui um indício de que a Diretoria da Sociedade não apenas está informada, mas valoriza a participação de sócios na implementação das políticas de avaliação em larga escala.

Desde o I SIPEM, realizado no ano 2000, encontramos referências aos resultados do SAEB como indicadores de baixo desempenho dos alunos ou de ineficácia do ensino (MAGINA; CAMPOS, 2000; PIRES, LOPES, FAINGUELERNT, 2000).

Ao longo da década, repetem-se as referências aos resultados das avaliações em larga escala como motivações para a proposição de mudanças no ensino. No IX ENEM, em 2007, uma mesa-redonda discute "resultados de programas de avaliação em larga escala: no caso da matemática em nível internacional, nacional e estadual" (OLIVEIRA; SOARES; SOARES, 2007).

No X ENEM, em 2010, Ortigão e Aguiar (2010) propõem um minicurso com o objetivo de "subsidiar professores e futuros professores do ensino fundamental e médio na apropriação dos resultados das avaliações em larga escala para que, a partir de suas leituras sobre o desempenho dos alunos em Matemática, possam repensar os currículos por eles ensinados nas escolas" (2010, p. 1). No V SIPEM, os mesmos autores apresentam trabalho sobre o Programme for International Student Assessment (PISA) (ORTIGÃO; AGUIAR, 2012).

Entretanto, são esparsos e escassos os registros de debate sobre as avaliações em larga 
escala como políticas, sobre as motivações dessas políticas, sobre os discursos que justificam essas avaliações - inclusive os recursos financeiros com elas despendidos - e sobre seus efeitos na educação escolar.

Uma discussão crítica às avaliações em larga escala é apresentada por Dione Lucchesi de Carvalho no VII ENEM, em sua intervenção na Mesa-Redonda "Educação Matemática de Jovens e Adultos". Carvalho (2001) observa estreita correspondência entre os objetivos do ensino de Matemática, enunciados nos Parâmetros Curriculares Nacionais do Ensino Médio (PCNEM), e os descritores de Matemática da Matriz Curricular de Referência do SAEB:

\begin{abstract}
$\mathrm{O}$ que estava sutilmente indicado nos PCN, fica caracterizado e operacionalizado via uma avaliação nacional. [...] Porém, ao ler os dois documentos podemos perceber que os professores não foram chamados a elaborar nenhum dos dois. Uma avaliação das competências detalhadas como estão nos descritores do documento do SAEB acabam atrelando o trabalho de sala de aula à eficácia da prova (CARVALHO, 2001, p. 4).
\end{abstract}

A autora argumenta que as pressões estabelecidas pelas avaliações agravam, ao invés de reverter, a histórica dualidade de percursos escolares (CARVALHO, 2001). Essa provocação, contudo, parece não ter encontrado eco em manifestações da Sociedade ou em trabalhos apresentados nos eventos subsequentes.

A discussão sobre os pressupostos e efeitos das avaliações em larga escala é retomada anos depois, no IV Fórum Nacional sobre Currículos de Matemática (IV FNCM), em 2017. Gomes e Petrucci-Rosa (2017) discutem a influência do ENEM nas práticas curriculares em um Instituto Federal. Antonio Miguel (2017), em sua participação na Mesa-Redonda "Currículo e avaliação: práticas e controvérsias", coloca em questão a

[...] legitimidade ético-política e epistemológica do empoderamento determinante que vem sendo atribuído às práticas avaliativas de desempenho escolar dos estudantes a ponto de tais práticas estarem transfigurando os valores de solidariedade, tolerância e encorajamento que deveriam prevalecer na relação entre professores e alunos (MIGUEL, 2017, p. 24).

Em artigo também recente, Antonio Miguel formula a provocação:

Todos se alarmam e se chocam com os resultados desastrosos de desempenho em matemática de nossos estudantes de todos os níveis da escola básica. Quase ninguém se interroga, porém, acerca dos jogos normativamente regrados de linguagem que orientam não só a produção das matrizes de avaliação do desempenho, com base nas quais se elaboram as questões das provas, mas que orientam também, os próprios pressupostos relativos ao conhecimento, à matemática e à aprendizagem, com base nos quais essas próprias matrizes são construídas (MIGUEL, 2016, p. 350).

Por que a discussão sobre as avaliações de larga escala não tem sido pautada na SBEM? Por que não nos interrogamos sobre a produção das matrizes de avaliação de 
desempenho $?^{9}$

Uma primeira explicação pode ser buscada nos interesses acadêmicos dos pesquisadores que compõem os diferentes GTs da SBEM. A legitimidade das avaliações em larga escala não tem sido objeto de discussão pelo GT 8, que trata de Avaliação; mas emergiu recentemente no FNCM, evento promovido pelo Grupo de Trabalho Currículo e Educação Matemática (GT 3), constituído em 2015 como encaminhamento do VI SIPEM.

Uma segunda explicação é a do "bombardeio cotidiano feito pelo discurso neoliberal e do qual somos todos vítimas, [pelo qual] acostumamo-nos tanto a correlacionar positivamente desempenho matemático escolar, inteligência ou talento individual e nível de desenvolvimento econômico de uma nação" (MIGUEL, 2016, p. 350).

Uma terceira explicação pode ser encontrada na legitimidade que a comunidade internacional de educadores matemáticos tem atribuído ao Programme for International Student Assessment (PISA). Autores reconhecidos no campo, como Jan de Lange, ligado ao Freudenthal Institute, ou Mogens Niss, da Dinamarca, compõem os Mathematics Expert Groups (MEGs) responsáveis pelo planejamento das provas. Mogens Niss (2015) sustenta que as provas são organizadas segundo a perspectiva da modelagem, uma importante tendência da Educação Matemática.

Entretanto, o que diz o PISA sobre a aprendizagem dos estudantes brasileiros? Quando consultamos os resultados da aplicação do exame em 2015, observamos que 43,7\% dos estudantes brasileiros que realizaram a prova foram classificados como abaixo do nível de proficiência 1 em matemática e, portanto, sequer tiveram suas habilidades avaliadas (INEP, 2016). Podemos falar de modelagem, no caso de testes cujos enunciados não foram sequer lidos ou compreendidos por uma expressiva parcela dos estudantes?

O segundo exemplo que trago para a discussão é o dos currículos para o Ensino Fundamental, um tema que foi, durante um bom período, tangenciado nos debates da SBEM.

Nos primeiros tempos da SBEM, os Encontros eram espaço de troca sobre as propostas curriculares gestadas e experimentadas nos Estados e Municípios (ENEM, 1988; 1990).

$\mathrm{Na}$ segunda metade dos anos 1990, várias lideranças da SBEM participam da produção dos Parâmetros Curriculares Nacionais para o Ensino Fundamental (PCNs) como

\footnotetext{
${ }^{9}$ Cabe registrar importantes avanços nesse debate, no ano de 2018. O livro "Currículos de Matemática em debate" (GODOY; SILVA; SANTOS, 2018), produzido a partir do IV FNCM, apresenta reflexões sobre o currículo, contemplando o tema da avaliação. O tema também foi tratado na Mesa-Redonda "Políticas públicas e Pesquisa em Educação Matemática Escolar", no VII SIPEM. Maria Isabel Ramalho Ortigão, coordenadora do GT 8, organizou a publicação de coletânea sobre o PISA (ORTIGÃO, 2018).
} 
redatores ou pareceristas. Celia Carolina Pires é uma das redatoras dos PCNs para os anos iniciais e Antonio José Lopes (Bigode) figura nos agradecimentos (BRASIL, 1997). Celia Carolino Pires e Ruy César Pietropaolo são redatores dos PCNs para os anos finais do Ensino Fundamental; dentre os consultores constam os nomes de Luiz Roberto Dante, Nilza Eingenheer Bertoni, Paulo Figueiredo Lima, Rômulo Campos Lins e Ubiratan D’Ambrósio (BRASIL, 1998). Pietropaolo registra que, entre os pareceristas, não há consenso acerca da necessidade da existência do documento:

\begin{abstract}
Salientamos que, apesar do elevado índice de pareceres considerando válida a iniciativa do Ministério da Educação, fundamentalmente por servirem de contraponto às veiculadas por muitos livros didáticos, não se pode dizer que houve total consenso sobre a necessidade dos PCN nesse atual momento. Houve pareceristas - poucos, mas enfáticos - que se contrapuseram à existência desses documentos (PIETROPAOLO, 2000, p. 71).
\end{abstract}

Os PCNs são objeto de debate no VI ENEM, em 1998. Na mesa-redonda "Políticas Públicas, PCNs e Educação Matemática", Bigode formula vários questionamentos ao processo de produção do documento: “Os PCNs são necessários? Quem deve definir parâmetros curriculares? Como deveria ser o processo de definição dos currículos? Deveria haver um currículo mínimo nacional?” (LOPES, 1998, p. 128). Em outra direção, Tania Campos valoriza a aproximação entre o documento e os debates realizados na SBEM:

Com certeza seria excelente se o processo de elaboração/discussão tivesse sido mais abrangente; todavia, o que o documento propõe, parece-me contemplar de forma bastante satisfatória as ideias veiculadas nos diferentes encontros de educação matemática - nacionais e regionais - que vêm acontecendo em nosso país (CAMPOS, 1998, p. 132).

O tema é retomado por Rômulo Campos Lins, na Conferência de Encerramento:

No Brasil a iniciativa e a condução do processo estiveram sempre nas mãos do MEC, e a comunidade participou oferecendo consultoria. É verdade que os PCN foram distribuídos a professores e professoras, e é verdade que o MEC espera uma discussão sobre eles. O ponto crucial, no entanto, é que a ideia de que eles deviam existir, e a decisão sobre o que deveriam ser partiu do MEC, e não de nós (LINS, 1998, p. 36).

A ausência de uma manifestação formal da entidade sobre os PCNs parece ser acompanhada de um tácito acordo com as linhas gerais dos documentos.

No I Fórum Nacional da SBEM sobre Currículos de Matemática, em junho de 2004, as diretorias regionais relatam que "Os PCN do Ensino Fundamental são conhecidos pelos professores, há uma boa aceitação das propostas, consideradas afinadas com a produção atual da área de Educação Matemática" (FNCM, 2004, p. 6). No debate, são mencionados como "avanços" dos PCN "o debate sobre temas como formação para a cidadania, transversalidade, resolução de problemas, história da matemática, conhecimentos prévios dos alunos, uso das tecnologias" (FNCM, 2004, p. 7). Pode-se perceber ambiguidade no tocante ao dilema entre 
padronização e autonomia curricular, quando se declara que

[...] embora os PCN indiquem algumas expectativas de aprendizagem, elas devem ser interpretadas em cada unidade escolar, em cada sala de aula. $\mathrm{O}$ desenvolvimento de um currículo deve ser acessível a todos os alunos, para que não caiamos na armadilha de cobrar de todos os alunos o que só uns poucos podem cumprir. Ao mesmo tempo, é necessário também não cair nas armadilhas do 'paternalismo' ou da 'discriminação', que têm privado alunos das camadas populares do acesso a conhecimentos importantes para sua formação (FNCM, 2004, p. 7).

No VIII ENEM, realizado um mês após o FNCM, a então Presidente Celia Maria Carolino Pires reivindica posicionamento e envolvimento da SBEM com o "aperfeiçoamento" dos PCNs:

[...] considero que não devemos partir da estaca zero, desconsiderando o trabalho de muitos educadores e mesmo, o investimento do dinheiro público que resultou na publicação dos PCN. Entendo que os princípios gerais, no caso dos PCN de Matemática, para o Ensino Fundamental e para o Ensino Médio, não confrontam com o que a comunidade de educadores matemáticos vem discutindo em seus encontros. Mesmo assim, a SBEM está discutindo essa questão e deve dar indicações sobre isso (PIRES, 2004, p. 11).

Em 2009, o MEC deflagra um processo de debate sobre política curricular que culmina com a produção do documento "Por uma política curricular para a educação básica: contribuição ao debate da base nacional comum a partir do direito à aprendizagem e ao desenvolvimento" (BRASIL, 2014b). Entre os elaboradores do documento estão Cristiano Muniz, presidente da SBEM de 2010 a 2013, e outros educadores matemáticos, como Ana Paula Jahn e Iole de Freitas Druck.

No V SIPEM, Celia Carolino novamente faz referência à inexistência de um posicionamento da SBEM sobre os PCNs: "no Brasil, uma série de questões permanecem como tabu que não se discute. É o caso da existência ou não de um currículo prescrito nacionalmente, os benefícios ou malefícios de sua adoção" (PIRES, 2012, p. 3). E propõe um GT sobre organização e desenvolvimento curricular em Matemática

[...] onde pesquisadores da área de Educação Matemática possam apresentar e debater resultados de pesquisa sobre teorias, concepções, princípios, organização, desenvolvimento, níveis de concretização e relações dos currículos com avaliação e com a formação de professores que ensinam Matemática (PIRES, 2012, p. 10).

Em 2013 e 2015, são realizados o II e o III Fóruns Nacionais sobre Currículos de Matemática; a intensificação do debate sobre o tema, contudo, não se reflete em tomada de posição sobre os currículos.

As manifestações da SBEM se darão no contexto da coleta, por parte do MEC, de “contribuições” à versão preliminar da Base Nacional Curricular Comum (BNCC) (BRASIL, 2015b). A SBEM é convidada para reunião com o MEC em maio de 2015 e a partir daí os Grupos de Trabalho são provocados a se manifestarem. O documento do MEC é tornado 
público em setembro e discutido no VI SIPEM, em novembro, em reunião que conta com a presença de Ítalo Modesto Dutra, então diretor de Currículos e Educação Integral do Ministério.

Após o SIPEM, é elaborada a segunda versão do documento "Contribuições da SBEM para a Base Nacional Comum Curricular", a partir dos GTs e de contribuições de sócios ou membros da comunidade. Dentre outras críticas, o documento aponta que a versão preliminar da BNCC "não apresenta uma coerência interna entre objetivos gerais iniciais e da área de matemática, entre o que se pensa e conteúdo, objetivos e operacionalização" (SBEM, 2016a, p. 5); “está desvinculado das principais tendências matemáticas apontadas por muitos estudos e pesquisas, o que, de certo modo, representa um retrocesso em relação aos avanços conquistados em outros documentos, citando especialmente os PCN" (SBEM, 2016a, p. 6); "parece estranho que um documento que valoriza a interdisciplinaridade não se refira de forma mais intensa a uma Educação Matemática Crítica, considerando principalmente a formação para a cidadania a ser tratada pela Educação Básica” (SBEM, 2016a, p. 7).

O tom geral do documento é de estranheza e descontentamento com o documento da BNCC. Contudo, a SBEM não se manifesta contrariamente à discussão da BNCC: "A grande maioria das pessoas envolvidas com a SBEM é favorável à discussão da BNCC, visto que esta discussão favorece debates e reflexões e, possivelmente o delineamento de um novo rumo para a educação no país, mas em uma única voz apelam para que esta não seja uma ação isolada" (SBEM, 2016a, p. 30). O documento da SBEM também não se manifesta contra a versão da BNCC, o tom é mais cauteloso:

\begin{abstract}
nossos colaboradores destacam que o documento preliminar da BNCC não traz uma proposta renovadora. [...] Destaca-se a necessidade de orientação para que o professor possa trabalhar a BNCC da forma como se espera que ela aconteça. Alguns temem que a base se transforme 'no todo' e que os currículos escolares se limitem a esses $60 \%$ (SBEM, 2016a, p. 31).
\end{abstract}

E o documento finaliza: "A SBEM segue disposta a participar com seus pares das discussões pertinentes a Educação Matemática no nosso país” (SBEM, 2016a, p. 35).

Como sabemos, o processo de discussão da BNCC, a partir de 2016, foi ainda mais restrito do que aquele que havia gerado a versão preliminar de 2015 . Pareceres $\operatorname{críticos}^{10}$ e algumas centenas de contribuições, conforme levantamento realizado por Bigode (2019), não foram considerados na versão final, aprovada e homologada em 2017.

\footnotetext{
${ }^{10}$ Lopes (2018) elenca as análises de Cristiano Alberto Muniz, Iole Freitas Druck, Adair Mendes Nacarato, Cármen Lúcia Brancaglion Passos e Maria Alice Gravina como "severamente críticas em relação aos propósitos, o processo, a estrutura e os conteúdos da BNCC".
} 
Já a BNCC do Ensino Médio foi encaminhada pelo governo Michel Temer em articulação com a reforma do Ensino Médio. A SBEM é signatária de nota encaminhada pela Associação Nacional de Pós-Graduação e Pesquisa em Educação (ANPEd) e várias outras entidades do campo da educação, em junho de 2018, que afirma:

\begin{abstract}
Não faz sentido que uma BNCC eleja apenas português e matemática como disciplinas obrigatórias, uma vez que a LDB indica um conjunto muito mais amplo de conhecimentos essenciais ao pleno desenvolvimento humano. [...] entendemos que o CNE precisa reafirmar a existência e vigência das Diretrizes Curriculares para a Educação Básica e as Diretrizes Curriculares para o Ensino Médio, já aprovadas por este Conselho, e que orientam de maneira adequada a formulação das propostas pedagógicas das escolas brasileiras considerando a diversidade e a autonomia necessárias à construção cotidiana de escolas democráticas que respeitem e valorizem as juventudes e garantam as possibilidades de pleno desenvolvimento humano e oportunidades justas, contribuindo para a redução das desigualdades em nosso país (NOTA DAS ENTIDADES..., 2018, p. 1).
\end{abstract}

O terceiro exemplo de política educacional que trago ao debate é o da discussão sobre os currículos das licenciaturas, desenvolvido e atualizado em vários momentos e em diferentes fóruns da SBEM.

Ao final do III ENEM, em 1990, a Assembleia Geral da SBEM aprova várias recomendações sobre os cursos de Licenciatura, incluindo as de "efetivo trabalho integrado entre os professores de disciplinas de conteúdo matemático e de disciplinas de conteúdo pedagógico", "prática de ensino em vários momentos ao longo do curso", "disciplinas da área de Educação Matemática, contemplando conhecimento crítico de propostas alternativas e novas metodologias de ensino e dos objetivos do ensino da matemática" (ENEM, 1990, p. 255).

Em 1996, a LDB extingue os currículos mínimos e atribui ao Conselho Nacional de Educação (CNE) a elaboração das Diretrizes para os cursos superiores. As Diretrizes Gerais para a Formação de Professores da Educação Básica em Nível Superior são produzidas em amplo processo de debate do qual a SBEM participa, e que desemboca nas Resoluções $\mathrm{n}^{\mathrm{o}} 1 \mathrm{e}$ $\mathrm{n}^{\mathrm{o}} 2$ do Conselho Pleno do CNE, de 2002. As Diretrizes reconhecem as licenciaturas como cursos com identidade própria, orientada para a formação de professores, e contemplam vários dos elementos apontados pela Assembleia da SBEM em 1990.

No mesmo período, são produzidas as Diretrizes Curriculares Nacionais para os cursos de Matemática. Em agosto de 2002, a SBEM realiza um Fórum Nacional de Licenciatura em Matemática que avalia o Parecer $n^{\circ} 1.302 / 2001$ da Câmara de Ensino Superior do CNE como um retrocesso em relação às discussões que vinham sendo feitas sobre o assunto e, inclusive, contraditório com as recém aprovadas Diretrizes Gerais para as Licenciaturas.

O Parecer não reconhece a licenciatura como um curso com identidade própria, mas 
apenas diferencia a formação do professor da do bacharel por meio de uma educação 'menos sólida', ou superficial; considera que apenas o bacharelado prepara para a pesquisa e o ensino superior, negando a licenciatura como espaço de formação dos formadores e desconhecendo a Educação Matemática como campo de pesquisa.

Segundo o documento da SBEM, o Parecer mostra o "desconhecimento da existência de uma sociedade representativa de professores e pesquisadores que têm produzido conhecimento sobre a Educação Matemática que supera uma visão da formação pela justaposição de conteúdos" (SBEM, 2003a, p. 41). As críticas são enviadas ao MEC; mas a Resolução no 3 é aprovada pela Câmara de Ensino Superior do CNE em fevereiro de 2003 nos mesmos termos do Parecer $n^{\circ} 1.302$.

Em abril de 2003, a SBEM realiza o I Seminário Nacional "Construindo propostas para os Cursos de Licenciatura em Matemática", em Salvador, que resulta em um novo documento (SBEM, 2003a). Em outubro de 2003, a Presidente Celia Carolino relata ao Conselho Nacional Deliberativo vários convites da Secretaria de Educação Média e Tecnológica (SEMTEC) do Ministério da Educação (MEC) à SBEM: para a elaboração de uma revista, para participação em ações de formação de formadores, para a discussão sobre os Parâmetros Curriculares Nacionais (PCNs). Nessa reunião, Mônica Rabello de Castro observa que:

as discussões realizadas com as Diretrizes para a Licenciatura produziram um documento mais maduro, a Sociedade ganha força com os documentos gerados em fóruns. Temos que viabilizar essa prática para podermos ter documentos prontos quando houver demanda do MEC sobre apreciações (SBEM, 2003b, p. 3).

A experiência da produção dos documentos pelos Fóruns, portanto, não apenas contribui para modificar os termos da relação com o MEC, mas institui um novo modo de construção de posicionamentos da SBEM.

A discussão sobre as licenciaturas segue intensa e articulada, com a realização de novos Fóruns Nacionais. Do II Fórum Nacional, em 2007, resultou carta ao MEC, reivindicando a não homologação do Parecer CNE/CP 5/2006, que revogava a Resolução 2/2002 e regulamentava a modalidade de diplomação em licenciatura por meio dos denominados Programas Especiais de Formação Pedagógica de Docentes (SBEM, 2007). O parecer não foi homologado.

No III Fórum Nacional, em 2009, foi debatida a redução da oferta de cursos de Licenciatura em Matemática (FÓRUM NACIONAL, 2009). As conclusões do IV Fórum Nacional, em 2011, reiteram a preocupação com o esvaziamento das licenciaturas e tratam da "urgência de se pensar a Licenciatura em Matemática no Brasil, ao mesmo tempo em que 
enfatizam o papel da SBEM em busca de melhores políticas públicas para a área” (FÓRUM NACIONAL, 2011, p. 5).

Também resultou desse Fórum a constituição de uma Comissão Paritária SBEM e SBM, com a participação de três membros de cada sociedade, para análise crítica dos Referenciais Curriculares Nacionais para Cursos de Licenciatura em Matemática, divulgados pelo Ministério da Educação (MEC) em 2010. Embora não tenha produzido mudanças nas diretrizes oficiais, o documento produzido pela comissão paritária é interessante porque registra um esforço de valorização das Licenciaturas em Matemática a partir da ação conjunta das duas sociedades (COMISSÃO PARITÁRIA SBEM SBM, 2013).

O texto da comissão, por outro lado, é objeto de reflexão crítica em palestra de Maria Laura Magalhães Gomes, quando avalia que

[...] embora [...] afirme que a formação matemática sintonizada com as questões da prática docente é um parâmetro essencial a ser observado na formação do licenciado em Matemática, ao apresentar-se de maneira muito genérica em relação a tal aspecto, pende acentuadamente para o lado do tratamento dos conteúdos do ponto de vista da matemática acadêmica (GOMES, 2016, p. 22).

A Assembleia Geral realizada ao final do XII ENEM, em 2016, aprova uma moção solicitando prorrogação do prazo para que as instituições que oferecem cursos de Licenciatura se adaptem às novas Diretrizes Curriculares Nacionais para formação inicial e continuada de professores, publicadas em julho de 2015. Várias manifestações de participantes da Assembleia expressam o acordo com o sentido geral das Diretrizes (SBEM, 2016b).

\section{Considerações finais}

Os três exemplos aqui mencionados indicam que as movimentações da SBEM em torno das políticas educacionais são, em larga medida, provocadas pelas iniciativas governamentais, mas também há uma dinâmica própria da Sociedade de definição dos temas que merecem ser objeto de manifestação, dos termos e dos procedimentos de construção desses posicionamentos. GTs e Fóruns dão sustentação a esses debates e, em alguns casos, também se constituem em meio ou a partir deles.

Os três exemplos também indicam que as discussões sobre políticas educacionais na SBEM estão fortemente ancoradas nas práticas e nas pesquisas dos educadores matemáticos. A sistematicidade e profundidade do debate sobre as licenciaturas certamente estão relacionadas aos afazeres dos formadores, que constituem expressiva parcela dos sócios frequentes aos eventos. Quanto às pesquisas, podemos pensar que conferem legitimidade, 
acuidade e profundidade aos posicionamentos da SBEM - como nos documentos que discutem as licenciaturas ou a BNCC - mas, por outro lado, de algum modo também condicionam os debates, que tendem a girar em torno dos conceitos e dos temas valorizados ou reconhecidos como legítimos pelos pesquisadores, e negligenciam outros temas, como os pressupostos que embasam as avaliações em larga escala ou os efeitos das políticas de padronização curricular.

Podemos identificar, ainda, algumas tendências nos modos como as discussões sobre as políticas educacionais vão se reconfigurando, ao longo do tempo.

Pode-se observar uma progressiva institucionalização da discussão das políticas, com a multiplicação das instâncias coletivas de debate (ENEMs, GTs, fóruns, regionais, CND, diretoria) e a valorização dessas instâncias.

Há também uma tendência à ampliação do escopo dos debates. Nos primeiros anos da SBEM, esses debates giravam em torno dos temas percebidos como relevantes nas práticas cotidianas dos educadores matemáticos - como a disputa de recursos para a pesquisa, e o reconhecimento da Educação Matemática pelas agências de fomento. Com o tempo, vão progressivamente se alargando, na direção dos temas que dizem respeito aos currículos, à formação de professores, alcançando até o tema mais geral do financiamento ou das finalidades gerais da educação escolar, como na recente manifestação sobre a PEC 241 (aprovada como EC 95/16) e a reforma do Ensino Médio (SBEM, 2016c).

Ao longo desses trinta anos, a SBM em vários momentos se constituiu como uma referência de modo de tratar as políticas educacionais, diferente e até mesmo oposta à da SBEM, nomeada como "tradicional" ou "palaciana" (SBEM, 2003b, p. 2-3), menos preocupada com a democratização da educação ou desconhecendo as produções da pesquisa no campo da Educação Matemática.

Houve, em sentido contrário, momentos de aproximação e até mesmo de cooperação, indicando que essas diferenças não são intrínsecas à existência e à história das duas sociedades. Por outro lado, o avanço dos debates - ou mesmo a sua postergação - revelam a existência, no interior da SBEM, de pontos de vista distintos e até mesmo divergentes sobre muitos temas, refletindo diferenças de vivências, inserções, concepções e até mesmo interesses.

É possível perceber, portanto, que ao longo de trinta anos, muito se avançou em termos dos modos de debater as políticas, dos temas considerados merecedores de manifestação por parte da sociedade e do reconhecimento da existência de diferentes perspectivas, entre os educadores matemáticos. Arriscaria dizer que, apesar da dificuldade, 
por muitos identificada, de congregar os professores que atuam na Educação Básica e com as ressalvas já mencionadas, a SBEM é uma entidade mais reconhecida, mais democrática, mais plural e mais crítica às políticas educacionais do que ao tempo de sua fundação e, nesse sentido, vem cumprindo o já mencionado preceito estatutário de "atuar [...] junto aos órgãos governamentais na formulação, implementação e avaliação de políticas nacionais de educação e, em especial, as relacionadas à Educação Matemática" (SBEM, 2013).

De outro lado, podemos dizer que avançamos na conquista de uma "Educação Matemática libertadora e democrática, acessível a todos" (PEREIRA, 2005, p. 156)? Em parte, se considerarmos que contribuímos para a implementação de políticas democratizantes e que boa parte das nossas pesquisas não apenas contribuem para, mas se desenvolvem nas salas de aula. O esvaziamento das licenciaturas, contudo, é um dentre muitos sinais de que avançamos muito pouco - ou quem sabe até regredimos - em relação às condições para se ensinar matemática na escola básica.

Os tempos se anunciam como mais difíceis para quem atua na educação e, em especial, na educação pública. Olhar para o passado pode nos ajudar a sobreviver nesses tempos difíceis? Penso que sim. Olhar para o passado nos permite perceber com mais nitidez em que aspectos e como avançamos, nos permite preservar a memória do que já foi experimentado e aquilo que justifica nossa existência como comunidade de educadores matemáticos que constroem a Sociedade Brasileira de Educação Matemática.

\section{Agradecimentos}

Agradeço a Antonio José Lopes (Bigode), Cristiano Alberto Muniz, José Carlos Pinto Leivas, Regina Célia Grando e Tania Maria Mendonça Campos, por terem, gentil e prontamente, concedido entrevistas que forneceram várias pistas para a consulta aos documentos. Entretanto, dadas as limitações para a elaboração do texto, os pontos de vista dos entrevistados não são aqui comentados; as reflexões apresentadas são de minha exclusiva responsabilidade.

\section{Referências}

BIGODE, A. J. L. Base, que base? O caso da Matemática. In: CÁSSIO, Fernando; CATELLI Jr., Roberto (Org.). Educação é a Base? 24 educadores discutem a BNCC. São Paulo: Ação Educativa, 2019. p. 139-159.

BRASIL. Constituição da República Federativa do Brasil. Brasília: 1988. Disponível em: <http: //www2.camara.leg.br/legin/fed/consti/1988/constituicao-1988-5-outubro-1988-322142- 
publicacaooriginal-1-pl.html>. Acesso em: 30 out. 2018.

BRASIL. Lei $\mathbf{n}^{0}$ 9.394, de 20 de dezembro de 1996. Estabelece as diretrizes e bases da educação nacional. Brasília: 1996.

BRASIL. Ministério da Educação. Secretaria de Educação Fundamental. Parâmetros Curriculares Nacionais: Matemática. Brasília: MEC, 1997. Disponível em: <http://portal.mec.gov.br/seb/arquivos/ pdf/livro03.pdf $>$. Acesso em: 30 out. 2018.

BRASIL. Ministério da Educação. Secretaria de Educação Fundamental. Parâmetros Curriculares Nacionais: Matemática ( $3^{\circ}$ e $4^{\circ}$ ciclos do ensino fundamental). Brasília: MEC, 1998. Disponível em: $<$ http://portal.mec.gov.br/seb/arquivos/pdf/matematica.pdf>. Acesso em: 30 out. 2018.

BRASIL. Lei n 13.005, de 25 de junho de 2014. Aprova o Plano Nacional de Educação - PNE e dá outras providências. Brasil: 2014a.

BRASIL. Ministério da Educação. Secretaria de Educação Básica. Diretoria de Currículos e Educação Integral. Por uma política curricular para a educação básica: contribuição ao debate da base nacional comum a partir do direito à aprendizagem e ao desenvolvimento. Brasília: MEC, 2014b. Versão preliminar.

BRASIL. Ministério da Educação. GT CAQ. Relatório Final. GT CAQ - Portaria 459, de 12 de maio de 2015. Brasília: 2015a. Disponível em: <http://pne.mec.gov.br/images/pdf/publicacoes/RELATOR IO_FINAL_GT_CAQ_out_15.pdf $>$. Acesso em: 30 out. 2018.

BRASIL. Ministério da Educação. Base Nacional Comum Curricular. Brasília: MEC, 2015b. Versão preliminar.

CABRITO, B. G. Avaliar a qualidade em educação: Avaliar o quê? Avaliar como? Avaliar para quê? Cadernos Cedes, Campinas, v. 29, n. 78, p. 178-200, maio/ago. 2009.

CAMPANHA NACIONAL PELO DIREITO À EDUCAÇÃO. CAQi e o CAQ no PNE: quanto custa a educação pública de qualidade no Brasil? São Paulo: 2018. Disponível em: $<$ http://www.custoaluno qualidade.org.br/pdf/quanto-custa-a-educacao-publica-de-qualidade-no-brasil.pdf $>$. Acesso em: 30 out. 2018.

CAMPOS, T. M. M. Políticas públicas, Parâmetros Curriculares Nacionais e Educação Matemática. In: ENCONTRO NACIONAL DE EDUCAÇÃO MATEMÁTICA, VI, São Leopoldo, 1998. Anais... São Leopoldo: SBEM/UNISINOS, 1998. v. I. p. 132-133.

CARVALHO, D. L. A Educação Matemática de Jovens e Adultos e o Ensino Médio. In: ENCONTRO NACIONAL DE EDUCAÇÃO MATEMÁTICA, VII, Rio de Janeiro, 2001. Anais... Rio de Janeiro: SBEM, 2001. p. 1-6.

COMISSÃO PARITÁRIA SBEM SBM. A Formação do Professor de Matemática no Curso de Licenciatura: Reflexões Produzidas pela Comissão Partidária SBM/SBEM. Boletim SBEM, n. 21, p. 2-42, fev. 2013.

ENCONTRO NACIONAL DE EDUCAÇÃO MATEMÁTICA, II, Maringá, 1988. Livro de resumos. Maringá: Universidade Estadual de Maringá, 1988.

ENCONTRO NACIONAL DE EDUCAÇÃO MATEMÁTICA, III, Natal, 1990. Anais... Natal: UFRN, 1990.

FIORENTINI, D. Rumos da pesquisa brasileira em Educação Matemática: o caso da produção 
científica em cursos de pós-graduação. 1994, 425 f. Tese (Doutorado em Educação) - Faculdade de Educação, Universidade Estadual de Campinas, Campinas, 2005.

FÓRUM NACIONAL DA SOCIEDADE BRASILEIRA DE EDUCAÇÃO MATEMÁTICA SOBRE CURRÍCULOS DE MATEMÁTICA (FNCM), I, São Paulo, 2004. Relatório. São Paulo: SBEM, 2004. Disponível em: < http://www.sbembrasil.org.br/files/forumI.pdf>. Acesso em: 30 out. 2018.

FÓRUM NACIONAL DE LICENCIATURAS EM MATEMÁTICA, III, Taguatinga, 2009. Relatório. Taguatinga: SBEM, 2009.

FÓRUM NACIONAL DE LICENCIATURAS EM MATEMÁTICA, IV, São Paulo, 2011. Relatório. São Paulo: SBEM, 2011.

FRIGOTTO, G. Os circuitos da história e o balanço da educação no Brasil na primeira década do século XXI. Revista Brasileira de Educação, v. 16, n. 46, p. 235-274, jan.-abr. 2011.

GOMES, M. L. M. Os 80 anos do primeiro curso de Matemática brasileiro: em busca de sentidos para uma comemoração relativa à formação de professores no Brasil. In: FÓRUM NACIONAL DE LICENCIATURAS EM MATEMÁTICA, V, Londrina, 2014. Anais... Londrina: SBEM, 2016. p. 1424.

GOMES, A. N.; PETRUCCI-ROSA, M. I. Currículos e práticas curriculares de Matemática no Ensino Médio Integrado de um Instituto Federal. In: FÓRUM NACIONAL SOBRE CURRÍCULOS DE MATEMÁTICA, IV, São Paulo, 2017. Anais... São Paulo: SBEM/USP, 2017. p. 72-81.

INSTITUTO NACIONAL DE ESTUDOS E PESQUISAS EDUCACIONAIS ANÍSIO TEIXEIRA INEP. Estatísticas da Educação Básica no Brasil. Brasília: INEP, 1996. Disponível em: <http://porta l.inep.gov.br/informacao-da-publicacao/- /asset_publisher/6JYIsGMAMkW1/document /id/486988>. Acesso em: 30 out. 2018.

INSTITUTO NACIONAL DE ESTUDOS E PESQUISAS EDUCACIONAIS ANÍSIO TEIXEIRA INEP. Brasil no PISA 2015. Sumário Executivo. Brasília: INEP, 2016. Disponível em: < http://downlo ad.inep.gov.br/acoes_internacionais/pisa/documentos/2016/pisa_brasil_2015_sumario_executivo.pdf $>$. Acesso em: 30 out. 2018.

LINS, R. C. A E(e)ducação M(m)atemática que praticamos. In: ENCONTRO NACIONAL DE EDUCAÇÃO MATEMÁTICA, VI, São Leopoldo, 1998. Anais... São Leopoldo: SBEM/UNISINOS, 1998. v. I. p. 36-37.

LOPES, A. J. Políticas públicas, PCNs e Educação Matemática. In: ENCONTRO NACIONAL DE EDUCAÇÃO MATEMÁTICA, VI, São Leopoldo, 1998. Anais... São Leopoldo: SBEM/UNISINOS, 1998. v. I. p. 128-9.

MACEDO, E. Base Nacional Curricular Comum: novas formas de sociabilidade produzindo sentidos para educação. Revista e-Curriculum, São Paulo, v. 12, n. 3, p. 1530 -1555, out./dez. 2014.

MAGINA, S.; CAMPOS, T. Adição nem sempre é fácil: um estudo diagnóstico. In: SEMINÁRIO INTERNACIONAL DE PESQUISA EM EDUCAÇÃO MATEMÁTICA, I, Serra Negra, 2000. Livro de resumos. Serra Negra: SBEM, 2000. p. 49-55.

MIGUEL, A. Desconstruindo o mérito da escola meritocrática: uma profissão de fé. In: FÓRUM NACIONAL SOBRE CURRÍCULOS DE MATEMÁTICA, IV, São Paulo, 2017. Anais... São Paulo: SBEM/USP, 2017. p. 24.

MIGUEL, A. Entre jogos de luzes e de sombras: uma agenda contemporânea para a educação 
matemática brasileira. Perspectivas da Educação Matemática, v. 9, n. 20, p. 323-365, 2016.

MUNIZ, N. C. Relatos de memórias - a trajetória histórica de 25 anos da Sociedade Brasileira de Educação Matemática (1988 - 2013). São Paulo: Livraria da Física, 2013.

NISS, M. Mathematical competencies and PISA. In: STACEY, K.; TURNER, R. (Eds.) Assessing Mathematical Literacy. The PISA Experience. Cham: Springer, 2015. p. 35-55.

NOTA DAS ENTIDADES SOBRE A AUDIÊNCIA PÚBLICA DO CNE SOBRE A BNCC DO ENSINO MÉDIO. São Paulo: 2018. Disponível em: < http://www.anped.org.br/news/nota-dasentidades-sobre-audiencia-publica-do-cne-sobre-bncc-do-ensino-medio>. Acesso em: 4 nov. 2018.

OLIVEIRA, L. K. M.; SOARES, J. F.; SOARES, M. T. C. Avaliação em larga escala: o caso da Matemática. In: ENCONTRO NACIONAL DE EDUCAÇÃO MATEMÁTICA, IX, Belo Horizonte, 2007. Anais... Belo Horizonte: SBEM, 2007. p. 1.

OLIVEIRA, R. P. Da universalização do Ensino Fundamental ao desafio da qualidade: uma análise histórica. Educação \& Sociedade, Campinas, v. 28, n. 100, p. 661-690, out. 2007.

ORTIGÃO; M. I. R.; AGUIAR, G. S. Discutindo o currículo de Matemática a partir dos resultados dos alunos nas avaliações em larga escala. In: ENCONTRO NACIONAL DE EDUCAÇÃO MATEMÁTICA, X, Salvador, 2010. Anais... Salvador: SBEM, 2010. p. 1-10. Mini-curso.

ORTIGÃO; M. I. R.; AGUIAR, G. S. Letramento em matemática no PISA. In: SEMINÁRIO INTERNACIONAL DE PESQUISA EM EDUCAÇÃO MATEMÁTICA, V, Petrópolis, 2012. Anais... Petrópolis: SBEM, 2012. p. 1-21.

PEREIRA, D. J. R. História do movimento democrático que criou a Sociedade Brasileira de Educação Matemática - SBEM. 2005, 261 f. Tese (Doutorado em Educação) - Faculdade de Educação, Universidade Estadual de Campinas, Campinas, 2005.

PIETROPAOLO, R. C. Parâmetros Curriculares Nacionais de Matemática: um estudo dos pareceres. In: SEMINÁRIO INTERNACIONAL DE PESQUISA EM EDUCAÇÃO MATEMÁTICA, I, Serra Negra, 2000. Livro de resumos. Serra Negra: SBEM, 2000. p. 70-74.

PIRES, C. M. C.; LOPES, A. J.; FAINGUELERNT, E. K. Grupo de Trabalho 2 - Educação Matemática nas Séries finais do Ensino Fundamental. In: SEMINÁRIO INTERNACIONAL DE PESQUISA EM EDUCAÇÃO MATEMÁTICA, I, Serra Negra, 2000. Livro de resumos. Serra Negra: SBEM, 2000. p. 67-69.

PIRES, C. M. C. Orientações Curriculares para a Educação Básica. Qual O Caminho? In: ENCONTRO NACIONAL DE EDUCAÇÃ̃ MATEMÁTICA, VIII, Recife, 2004. Anais... Recife: SBEM, 2004. Palestra. p. 1-13.

PIRES, C. M. C. Pela criação de um Grupo de Trabalho sobre Currículos de Matemática, no SIPEM. In: SEMINÁRIO INTERNACIONAL DE PESQUISA EM EDUCAÇÃO MATEMÁTICA, V, Petrópolis 2012. Anais... Petrópolis: SBEM, 2012. Comunicação científica. p. 1-11.

SAVIANI, D. Política educacional brasileira: limites e perspectivas. Revista de Educação PUCCampinas, Campinas, n. 24, p. 7-16, jun. 2008.

SOCIEDADE BRASILEIRA DE EDUCAÇÃO MATEMÁTICA (SBEM). Subsídios para a discussão de propostas para os cursos de Licenciatura em Matemática: uma contribuição da Sociedade Brasileira de Educação Matemática. São Paulo: SBEM, 2003a. Documento produzido pelo I Seminário Nacional "Construindo propostas para os Cursos de Licenciatura em Matemática", 
Salvador, 2003.

SOCIEDADE BRASILEIRA DE EDUCAÇÃO MATEMÁTICA (SBEM). Ata da Nona Reunião do Conselho Nacional Deliberativo da SBEM. São Paulo: SBEM, 2003b. Disponível em: <http://ww w.sbembrasil.org.br/atas/cndoutubro2003.htm>. Acesso em: 30 out. 2018.

SOCIEDADE BRASILEIRA DE EDUCAÇÃO MATEMÁTICA (SBEM). Carta ao Secretário de Educação Superior do MEC, professor Ronaldo Mota. São Paulo: SBEM, 2007. Disponível em: $<$ http://www.sbembrasil.org.br/sbembrasil/images/Doc\%202.pdf>. Acesso em: 30 out. 2018.

SOCIEDADE BRASILEIRA DE EDUCAÇÃO MATEMÁTICA (SBEM). Carta ao Excelentíssimo Sr. Ministro de Estado de Educação, prof. Fernando Haddad. Brasília: SBEM, 2010a. Disponível em: <http://www.sbembrasil.org.br/sbembrasil/index.php/noticias/372-carta-ao-excelentissimo-sr-min istro-de-estado-de-educacao-prof-fernando-haddad>. Acesso em: 4 nov. 2018.

SOCIEDADE BRASILEIRA DE EDUCAÇÃO MATEMÁTICA (SBEM). SBEM frente à proposta de mestrado profissional da SBM. Brasília: SBEM, 2010b. Disponível em: <http://www.sbembrasil org.br/sbembrasil/index.php/noticias/358-sbem-frente-a-proposta-de-mestrado-profissional-da-sbm>. Acesso em: 30 out. 2018.

SOCIEDADE BRASILEIRA DE EDUCAÇÃO MATEMÁTICA (SBEM). Estatuto. Brasília: SBEM, 2013.

SOCIEDADE BRASILEIRA DE EDUCAÇÃO MATEMÁTICA (SBEM). Contribuições da SBEM para a Base Nacional Comum Curricular. Brasília: SBEM, 2016a. Disponível em: <http://www. sbembrasil.org.br/files/BNCC_SBEM.pdf>. Acesso em: 30 out. 1988.

SOCIEDADE BRASILEIRA DE EDUCAÇÃO MATEMÁTICA (SBEM). Ata da Assembleia Geral Ordinária realizada em 16 de julho de 2016, em São Paulo. São Paulo: SBEM, 2016b. Disponível em: <http://www.sbem.com.br/files/ata_2016.pdf>. Acesso em: 30 out. 2018.

SOCIEDADE BRASILEIRA DE EDUCAÇÃO MATEMÁTICA (SBEM). Manifesto sobre a Reforma do Ensino Médio e a Pec 241. Brasília: SBEM, 2016c. Disponível em: < http://www.sbembr asil.org.br/files/manifesto.pdf>. Acesso em: 30 out. 2016.

SOCIEDADE BRASILEIRA DE EDUCAÇÃO MATEMÁTICA (SBEM). Nota pública. Brasília: SBEM, 2018. Disponível em: <http://www.sbembrasil.org.br/sbembrasil/index.php /noticias/837-notapublica $>$. Acesso em: 4 nov. 2018.

SOCIEDADE BRASILEIRA DE MATEMÁTICA (SBM). Mestrado Profissional em Matemática em Rede Nacional - PROFMAT. Rio de Janeiro: 2018. Disponível em: <http://www.profmat-sbm.or g.br/organizacao/apresentacao/>. Acesso em: 30 out. 2018. 